\title{
Out-of-Body Experiences: All in the Brain?
}

\author{
Janice M. Holden, Ed.D. \\ University of North Texas, Denton, TX \\ Jeffrey Long, M.D. \\ Near-Death Experience Research Foundation, \\ Gallup, NM \\ Jason MacLurg, M.D. \\ Seattle, WA
}

\begin{abstract}
In 2002, four Swiss physicians published an article in the leading scientific journal Nature claiming to have induced an out-of-body experience (OBE) through focal electrical stimulation of the brain of a patient undergoing surgical evaluation for epilepsy treatment (Blanke, Ortigue, Landis, and Seeck, 2002). The article's subtitle authors claimed that "the part of the brain that can induce out-of-body experiences has been located" (Blanke, Ortigue, Landis, and Seeck, 2002, p. 269) and the subtitle of the accompanying report on the journal's website read "stimulating brain region elicits illusion often attributed to the paranormal" (Pearson, 2002). We present arguments supporting the conclusion that the subtitle claims were not well-founded and that much research remains to be conducted to unravel the mystery of OBEs.
\end{abstract}

KEY WORDS: out-of-body experience; temporal lobe; brain stimulation.

A one-page print article in 2002 in the journal Nature was provocatively titled "Stimulating illusory own-body perceptions: The part of the brain that can induce out-of-body experiences has been located" (Blanke, Ortigue, Landis, and Seeck, 2002, p. 269). The

Janice M. Holden, Ed.D., is Professor of Counseling and Interim Chair of the Department of Counseling, Development, and Higher Education in the College of Education at the University of North Texas in Denton, TX. Jeffrey Long, M.D., is a radiation oncologist and founder of the Near-Death Experience Research Foundation (www.nderf.org). Jason MacLurg, M.D., is a psychiatrist in private practice. Reprint requests should be sent to Dr. Holden at the College of Education, University of North Texas, P. O. Box 310829, Denton, TX 76203-0829; e-mail: holden@coe.unt.edu. 
accompanying notice on the journal's Internet website was similarly titled "Electrodes trigger out-of-body experience: Stimulating brain region elicits illusion often attributed to the paranormal" (Pearson, 2002), and began with the statement, "Activity in one region of the brain could explain out-of-body experiences. Researchers in Switzerland have triggered the phenomenon using electrodes." These articles were given substantial attention by the mass media. Because many near-death experiencers (NDErs) report an out-of-body experience (OBE) as part of their NDEs, this research could be relevant to an understanding of NDEs. We therefore undertook to examine the matter in some detail.

\section{Summary of the Article}

The article's four authors, Olaf Blanke, Stéphanie Ortigue, Theodor Landis, and Margitta Seeck, neurologists and neurosurgeons at Geneva and Lausanne University hospitals in Switzerland, reported findings they had made during a brain operation to alleviate a patient's seizures. The 43-year-old woman's symptoms indicated epilepsy in the right temporal lobe, an area of the brain located above and behind the right ear. Because imaging techniques did not reveal the exact brain location associated with her seizures, they opened her skull and probed several areas to locate the defective portion, a process known as "brain mapping." The brain itself does not feel pain, so the patient can be conscious and can speak while physicians probe various locations with minute amounts of electricity. Consequently, the patient was able to describe her experience during each electrical stimulation. In the process of searching for the site associated with her epilepsy, the physicians stimulated a specific area near the right temporal lobe called the right angular gyrus, and the patient reported intriguing sensations the authors called "out-of-body experiences." This brain area was not related to her epilepsy.

When the physicians first stimulated this area, the woman "reported that she was 'sinking into the bed' or 'falling from a height" (Blanke, Ortigue, Landis, and Seeck, 2002, p. 269). When they increased the electricity, she reported, "I see myself lying in bed, from above, but I only see my legs and lower trunk" (p. 269). The authors reported that "two further stimulations induced the same sensation, which included an instantaneous feeling of 'lightness' and 'floating' about two meters above the bed, close to the ceiling" (p. 269). 
The physicians then asked the patient to "watch her (real) legs during the electrical stimulation.... This time, she reported seeing her legs 'becoming shorter"' (Blanke, Ortigue, Landis, and Seeck, 2002, p. 269). The physicians went on to explain that if her legs were bent at a 90-degree angle before the stimulation, "she reported that her legs appeared to be moving quickly towards her face, and took evasive action" (p. 269). The authors continued:

When asked to look at her outstretched arms during the electrical stimulation ... the patient felt as though her left arm was shortened; the right arm was unaffected. If both arms were in the same position but bent by 90 degrees at the elbow, she felt that her left lower arm and hand were moving towards her face.... When her eyes were shut, she felt that her upper body was moving toward her legs, which were stable. (p. 269)

The authors asserted that "these observations indicate that OBEs ... can be artificially induced by electrical stimulation of the cortex" (p. 269), and they went on to speculate about the mechanisms involved.

\section{Our Response to the Article}

How warranted is their assertion that they induced an OBE? In particular, the authors implied that their patient's experience was an OBE, that is, that it (1) fell within the definition of OBEs, and (2) was both representative of, and indistinguishable from, spontaneous OBEs. How accurate is that dual assumption?

Regarding the first assumption, Blanke and colleagues defined OBEs as "curious, usually brief sensations in which a person's consciousness seems to become detached from the body and take up a remote viewing position" (p. 269), a definition for which they cited three European publications (Brugger, Regard, and Landis, 1997; Grusser and Landis, 1991; Hécaen and Ajuriaguerra, 1952). American OBE researchers have offered somewhat similar definitions, for example: "An experience where you felt that your mind or awareness was separated from your physical body" (Gabbard and Twemlow, 1984, pp. 3-4); "An ... experience $\ldots$ in which the center of consciousness appears to the experient to occupy temporarily a position which is spatially remote from his/her body" (Irwin, 1985, p. 5); an experience in which "people feel that their 'self,' or center of awareness, is located outside of the physical body" (Alvarado, 2000, p. 183). By all of these definitions, the Swiss patient's experience qualified as an OBE. 
To begin to address the second assumption, that the Swiss patient's OBE was typical of spontaneous OBEs, consider the description of a spontaneous OBE by an English patient who "had suffered a displacement of the foot, which had been returned under an anaesthetic" (Green, 1968, p. 123):

Before coming round I saw myself up in a corner of the room and I was looking down upon the hospital bed. The bedclothes were heaped up over a cradle and my legs were exposed from the knees down.

Around the right ankle was a ring of plaster and below the knee was a similar ring. These two rings were joined by a plaster strip [on] each side of [the] leg. I was struck by the pink of my skin against the white plaster.

When I regained consciousness two nurses were standing a [sic] foot of bed looking at the operation, one quite young. They at once left the private ward and I managed to raise myself up and look over the cradle seeing again exactly what I had seen when still "out."

Being a hot day was perhaps why the bedclothes had been pulled away from my legs and were heaped over the cradle. The particular way in which the plaster had been applied was plainly seen from my position in the corner of room and the contrast between pink skin and white plaster was striking. (Green, 1968, p. 123)

Our comparison of the Swiss and English patients' OBE accounts revealed several important differences. First, the Swiss patient reported viewing only part of her body, specifically her legs and lower trunk, whereas the English patient viewed his entire body. Second, the Swiss patient did not view those body areas involved in her health concern or medical procedure, specifically her head or brain, whereas the English patient viewed those body parts involved in his health concern and medical procedure, specifically his leg and cast. Third, the Swiss patient reported distortion of body images, her legs and arm becoming shorter, whereas the English patient reported no distortion of body image. Fourth, the Swiss patient reported the illusion of bodily movement, her legs and arms moving toward her face and upper body moving forward, whereas the English patient reported no illusion of bodily movement.

In summary, the English patient's experience seemed quite realistic, whereas the Swiss patient's experience was unrealistic: fragmentary, distorted, and illusory. In fact, a thorough review of three classic books reporting extensive $\mathrm{OBE}$ research (Gabbard and Twemlow, 1984; Green, 1968; Irwin, 1985) and a recent review of the entire OBE research literature (Alvarado, 2000) revealed that the English patient's $\mathrm{OBE}$ is quite characteristic of OBEs in general, whereas the Swiss 
patient's is highly uncharacteristic. Regarding bodily distortion, for example, we found only one reference to bodily distortion during OBEs: a single instance reported by a person diagnosed with schizophrenia (Blackmore, 1986). Glen Gabbard and Stuart Twemlow (1984), after reviewing hundreds of OBE reports, concluded that "body image disturbances [are] unusual" (p. 118) during OBEs, even though such disturbances are commonly experienced whenever we fall asleep or are just beginning to wake up from sleep.

The absence of body distortion in spontaneous OBEs is substantiated by a review of hundreds of first-person accounts of spontaneous OBEs and NDEs submitted to the Internet websites of the OBE Research Foundation (OBERF) (www.oberf.org) and the NDE Research Foundation (NDERF) (www.nderf.org); virtually none of them included either distortion of body image or illusion of bodily movement.

A second important difference revealed by comparing the Swiss and English patients' experiences is the factor of lucidity, defined as "having full use of one's faculties" and finding an experience "clear to the understanding" (Merriam-Webster's Collegiate Dictionary, n.d.). Presumably, the Swiss patient would have been surprised or confused when, immediately after taking evasive action, the physicians discontinued electrical stimulation and she found that her limbs were not at all where she had just perceived them to be. By comparison, the English patient's description conveyed psychological continuity. That is, his OBE perceptions were followed by perceptions in bed that confirmed each another, indicating that during his OBE he had full use of his faculties and found the experience clear to his understanding. Apparently, he was lucid. Furthermore, the great majority of many hundreds of spontaneous OBEs, including OBEs within NDEs, that were reported to the OBERF and NDERF websites had been characterized by lucidity.

This attribute of lucidity is related to the observation of reality in most transpersonal experiences, experiences that transcend the usual physical limits of space and/or time. Upon returning to usual waking consciousness, a transpersonal experiencer typically looks back on the experience as having been real, or at least potentially real. By contrast, when people return to normal consciousness after a dream or a hallucination, they only rarely say that the dream or hallucination was even potentially real. Presumably, the Swiss patient would concur that at least much of her out-of-body perception was illusory rather than real. Conversely, the English patient, and most other spontane- 
ous OBErs, have reported their sense that the experience was real. The striking differences between the experience described by the electrically stimulated patient in the Nature article and the experiences of spontaneous OBErs can be seen by reviewing directly the many $\mathrm{OBE}$ and NDE accounts posted on three Internet sites: www.iands.org, www.oberf.org, and www.nderf.org.

The phenomenon of electrical stimulation of the right temporal lobe resulting in atypical out-of-body experiences is not new. This phenomenon was first reported by neurosurgeon Wilder Penfield in 1955. His procedure involved electrical stimulation of a location different from the one stimulated by the Swiss physicians, indicating that the "one" brain region associated with OBEs has not yet been located (Neppe, 2002). And significantly, some "memories" evoked in patients by Penfield's electrical stimulation of their brains turned out to be partially or totally nonfactual. For example:

One of Penfield's patients, when the electrode was applied, heard her mother calling in a lumberyard. A record of the past? No, it was not. The woman stated she had never in her life been near a lumberyard. Other patients' "recollections" turned out to be influenced greatly by the conversation between the doctor and patient in the two minutes preceding the electrical stimulation. (Ornstein, 1991, p. 189)

This finding further suggests that the Swiss patient described in the Nature article may have been experiencing an atypical state of consciousness rather than a typical OBE.

It is one thing for a physician to stimulate the brain electrically and produce a single aspect of an experience, such as contraction of the triceps muscle, causing a person's bent arm to straighten out. It is a vastly different thing for that same person to enact the intentional, meaningful, complex task of reaching out to grasp a teacup. Although the contraction of the triceps muscle is one component of the task of having tea, it lacks the holistic quality of the enacted experience, including intention, coordination, and so on. Analogously, electrical stimulation of the brain has not yet yielded a typical OBE. To assume that the brain is involved in or associated with out-of-body phenomena is one thing; but to imply, with phrases like "the part of the brain that can induce out-of-body experiences" and "OBEs ... can be artificially induced by electrical stimulation of the cortex" (Blanke, Ortigue, Landis, and Seeck, 2002, p. 269), that electrical stimulation of the brain produces typical OBEs is quite another. 
The professional near-death literature contains multiple reports of veridical perception of phenomena that were outside the range of the NDEr's sensory perception and, therefore, of brain mediation (Ring and Cooper, 1997; Ring and Lawrence, 1993; Sabom, 1982; Sharp, 1995; van Lommel, van Wees, Meyers, and Elfferich, 2001). In some cases, these perceptions occurred while the NDEr apparently was experiencing the brain inactivity that follows within 10 seconds of cessation of heartbeat (van Lommel, van Wees, Meyers, and Elfferich, 2001). More than a hundred such cases are published on the Internet websites mentioned above: www.iands.org, www.nderf.org, and www.oberf.org. Taken together, the evidence suggests strongly the possibility that near-death out-of-body perception might occur without the mediation of the physical senses or the brain. Therefore, to refer to OBEs in general as "illusions" is premature; scientists have not yet resolved the question of the accuracy of out-of-body perceptions nor, hence, the "reality" of the sense OBErs report of their consciousnesses functioning independent of their physical bodies. Even if future research convincingly demonstrated that electrical stimulation of a particular area of the brain consistently induced typical OBEs, this finding would not explain veridical perception associated with OBEs.

We believe it is inappropriate to conclude "the part of the brain that can induce out-of-body experiences has been located" (Blanke, Ortigue, Landis, and Seeck, 2002, p. 269) based on a single anecdotal observation, especially with the concerns we have presented. We are not aware of any other published accounts of the induction of purported OBE by electrical stimulation of the right angular gyrus. This observation is especially surprising given the enormous media interest in the article by Blanke and colleagues. It is possible that the single anecdotal account was an anomalous occurrence and extremely atypical of the results of neural electrical stimulation. In the absence of a significant number of additional published reports of phenomena similar to that described by Blanke, Ortigue, Landis, and Seeck (2002), it would be reasonable to hypothesize a correlation between neural electrical stimulation and OBE-like experiences, but unreasonable to conclude that the hypothesis was proven.

\section{Conclusion}

The question of the mechanism of OBEs is far from answered. Reports like those in the Nature article contribute valuable in- 
formation regarding this question, but they do not warrant a claim that OBEs might now be "explained." To their credit, the authors of the article closed with the disclaimer that they "do not fully understand the neurological mechanism that causes OBEs" (Blanke, Ortigue, Landis, and Seeck, 2002, p. 269). Unfortunately, that statement still implied the unwarranted conclusion that the cause of OBEs can be reduced to neurological mechanisms. These Swiss physicians elicited the patient's OBE-like sensations by their electrical stimulation of a small area of her brain. Electrical stimulation is a mechanism, not a cause. That is, the patient's experience was "caused" by the intentional action of the physician holding the probe. In the case of both intentional and spontaneous OBEs, the cause, that is, the external or internal trigger, has yet to be identified.

In summary, the Nature authors did not produce an OBE in their patient that was typical of spontaneous OBEs. Conclusions about the cause of OBEs cannot be made from their single anecdotal case report. Although their report might raise a hypothesis about a possible neural electrical mechanism involved in at least some OBE-like phenomena, the authors did not explain the cause of the phenomenon that so many OBErs have experienced spontaneously or by conscious effort. Finally, although they showed that some OBEs may involve illusory perceptions, they did not resolve the question of whether at least some spontaneous OBEs involve accurate, "real" perceptions. OBEs with veridical perception are not explainable by neurophysiological mechanisms alone. As the pioneering neurosurgeon Penfield concluded about the thorny issue of "mind-body dualism":

In the end, I conclude that there is no good evidence, in spite of new methods such as the employment of stimulating electrodes, ... that the brain alone can carry out the work that the mind does. I conclude that it is easier to rationalize man's being on the basis of two elements [brain and mind] than on the basis of one. But I believe that one should not pretend to draw a final scientific conclusion, in man's study of man, until the nature of the energy responsible for mindaction is discovered as, in my own opinion, it will be. (Penfield, 1975, p. 114)

\section{References}

Alvarado, C. S. (2000). Out-of-body experiences. In Cardeña, E., Lynn, S. J., and Krippner, S. (eds.), Varieties of anomalous experience: Examining the scientific evidence (pp. 183-218). Washington, DC: American Psychological Association. 
Blackmore, S. J. (1986). Out of body experiences in schizophrenia: A questionnaire survey. Journal of Nervous and Mental Disease, 174, 615-619.

Blanke, O., Ortigue, S., Landis, T., and Seeck, M. (2002). Stimulating illusory own-body perceptions: The part of the brain that can induce out-of-body experiences has been located. Nature, 419, 269-270.

Brugger, P., Regard, M., and Landis, T. (1997). Illusory reduplication of one's own body: Phenomenology and classification of autoscopic phenomena. Cognitive Neuropsychiatry, 2, 19-38.

Gabbard, G. O., and Twemlow, S. W. (1984). With the eyes of the mind: An empirical analysis of out-of-body states. New York, NY: Praeger.

Green, C. (1968). Out-of-the-body experiences. Oxford, England: Institute of Psychophysical Research.

Grusser, O. J., and Landis, T. (1991). Visual agnosias and other disturbances of visual perception and cognition. Amsterdam, The Netherlands: Macmillan.

Hécaen, H., and Ajuriaguerra, J. (1952). Méconnaissances et hallucinations corporelles. Paris, France: Masson.

Irwin, H. J. (1985). Flight of mind: A psychological study of the out-of-body experience. Metuchen, NJ: Scarecrow.

Merriam-Webster's Collegiate Dictionary. (n.d.). Retrieved September 25, 2002, from http://www.britannica.com/

Neppe, V. M. (2002). "Out of body experiences" (OBEs) and brain localisation: A perspective. Australian Journal of Parapsychology, 2, 85-96.

Ornstein, R. (1991). Evolution of consciousness: The origins of the way we think. New York, NY: Touchstone.

Pearson, H. (2002). Electrodes trigger out-of-body experience. Retrieved September 25, 2002, from: www.nature.com/nsu/020916/020916-8.html

Penfield, W. (1975). The mystery of the mind: A critical study of consciousness and the human brain. Princeton, NJ: Princeton University.

Ring, K., and Cooper, S. (1997). Near-death and out-of-body experiences in the blind: A study of apparent eyeless vision. Journal of Near-Death Studies, 16, 101-147.

Ring, K., and Lawrence, M. (1993). Further evidence of veridical perception during neardeath experiences. Journal of Near-Death Studies, 11, 223-229.

Sabom, M. B. (1982). Recollections of death: A medical investigation. New York, NY: Harper and Row.

Sabom, M. (1998). Light and death: One doctor's fascinating account of near-death experiences. Grand Rapids, MI: Zondervan.

Sharp, K. C. (1995). After the light: The spiritual path to purpose. New York, NY: Avon.

van Lommel, P., van Wees, R., Meyers, V., and Elfferich, I. (2001). Near-death experience in survivors of cardiac arrest: A prospective study in the Netherlands. Lancet, 358, 2039-2045. 